\title{
Analysis on the Pricing Strategy Choice of Cross-regional Toll Transport Corridor Pengrui Bai ${ }^{*}$, Haicheng $\mathrm{Xu}$ \\ School of Economics and Management, Chang'An University, China \\ ${ }^{*}$ Corresponding author: Pengrui Bai, Ph.D, baipengrui666@163.com
}

\begin{abstract}
Because local governments raise money and build the toll road in China, the regional surplus is primary consideration when pricing the standard of the regional road. According on the pricing principle of the cross-regional toll transport corridor, the paper analyzes the factors that affect regional surplus and total social surplus. Firstly the paper determines the pricing strategy of the single toll road on the perspective of road users, and gives ten kinds of comprehensive pricing strategy for the two cross-regional connected roads. Then the paper analyzes the formation mechanism of the five special pricing strategies on the view of economy and society. Finally, the paper provides the theoretical basis for determining the comprehensive pricing standard of the cross-regional transport corridor.
\end{abstract}

Key words: highway transportation; cross-regional toll roads; transport corridor; pricing strategy; the regional and social surplus

\section{Introduction}

2015 is the final year of the twelfth five-year plan in China. Looking back on the five years, transportation industry has made great achievements with national economy and social development. In 2012, the state council of China issued the twelfth five-year plan of comprehensive transportation system, officially presented integrated transport channel of five longitudinal and five horizontal and the international regional transport corridor ${ }^{1}$. Connecting to the regional economic centre, the important industry \& agriculture and energy production and sales' base through these transport channels realizes the economical shift from developed regions to the less developed regions, and reduces the economic gap of the western, central and eastern. As an important part of transport corridor, toll road can regulate the regional economic balance and achieve the plan, so how to change a pricing strategy to realize the maximize the economic value of the toll road becomes the key. In this paper, we analyse the pricing principle of cross-regional toll transport channel, and study comprehensive pricing strategy of the cross-regional toll transport corridor for the goal of regional surplus maximization after consider road users by region, so as to provide reference for making strategy in reality.

\section{Transport corridors of cross-regional toll road and pricing principle}

Transport corridor which is also called transport passage, scholars at home and abroad have different definition ${ }^{2}$.Toll transport corridors are a belt transport route and transport facilities through toll road connecting different regions, which is important, convenient, advanced technology and extensible ${ }^{3}$. Connecting the main social and economic centre and production and sale' base of industry \& agriculture is the main role of transport corridor. In 1985, the first toll road of China was had built, China enters the peak period of construction of toll roads. 
But the central government was difficult to bear the huge construction funds of road, it take to construct after financing way by the provinces in China. Because of the construction fund raising way, different region make different pricing standard, and country just makes the classification criteria of motorcycle models on toll road.

The provinces firstly measure pricing strategy meets the surplus maximum principle of toll road's region when the region formulate charging standards of toll road. This principle accords with the purposes which the construction of local government is to create economic income.

$$
\max _{\tau_{i}^{0}, \sigma_{i}^{0}} L S=\int_{0}^{Y_{i}} P^{Y_{i}}(y) d y-c^{Y_{i}}\left(Y_{i}\right) Y_{i}+\left(\tau_{i}^{0} X_{i}+\sigma_{i}^{0} Y_{i}\right)+\left(I_{X_{i}} V^{X_{i}}+I_{Y_{i}} V^{Y_{i}}\right)
$$

Derivative of Eq. (1). equals to 0. LS consists of local surplus, toll income and fee income ${ }^{4}$. Secondly, consider that the total social surplus value of whole cross-regional toll road transport corridor is a loss or not.

$$
S S=\int_{0}^{Y_{i}} P^{Y_{i}}(y) d y-c^{Y_{i}}\left(Y_{i}\right) Y_{i}+\int_{0}^{X_{i}} P^{X_{i}}(x) d x-c^{X_{i}}\left(X_{i}\right) X_{i}+\left(\tau_{i}^{0} X_{i}+\sigma_{i}^{0} Y_{i}\right)+\left(I_{X_{i}} V^{X_{i}}+I_{Y_{i}} V^{Y_{i}}\right)-d(\xi)
$$

In the Eq. (2), $S S \geq 0$ has a solution at least. $S S$ consists of $L S$ and the cost of connection between two roads.

When satisfying $L S$ of toll road, the government who own road will consider SS, this principle is the central government and local government to consider the results of the overall efficiency about transport corridor. Base on the above two principles, the following, combining with other factors, analyzes comprehensive pricing strategy of cross-regional toll transport corridor in China from pricing reasons and so on.

\section{Analysis on the pricing strategy of cross-regional toll transport corridor in China}

For cross-regional toll transport corridor made up of two roads, the construction of the two roads is completed by two different governments, so regional pricing firstly considers local surplus maximization, then considers total society surplus of two roads. According to the vehicle ownership, road users can be divided into local and cross-regional transport vehicle traffic $^{5}$. For vehicle of toll road, the four pricing standard can be formed by toll difference: different toll $\left(\tau_{i}^{1}, \sigma_{i}^{1}\right)$ between local transport and cross-regional transport, uniform toll $\left(\theta_{i}^{2}\right)$ between local transport and cross-regional transport, local transport toll $\left(\sigma_{i}^{3}\right)$ and crossregional transport toll $\left(\tau_{i}^{4}\right)$. For cross-regional toll transport corridor composed of two roads, if road A and B is head-to-tail ligation, road users of two roads are divided into two kinds, and consider only one direction of traffic flow (from A to B), two roads exist dependence and competition, and vehicle on the road $\mathrm{A}$ has the potential to use road $\mathrm{B}$, not existence on the contrary. It will lead to a phenomenon that traffic distribution time, traffic and traffic capacity on the road A will inevitably affect them of the road B. Because road A connects into road B for the geographic region, both of transport demand is bound to affect the regional economic benefit. Although transport demand of the road A and B will change over time, road A will wage price war on road B to get more profits because of not fully observing change. Price war 
makes roads' toll fluctuate between the price level of conspiracy and the competitive price level, equilibrium will come out between conspiracy period and price war period and show 10 kinds of pricing strategy. The following detailedly analysis five kinds of strategy.

\subsection{Different toll on the road $A$ and $B\left(\tau_{A}^{1}, \sigma_{A}^{1}, \tau_{B}^{1}, \sigma_{B}^{1}\right)$}

Both road $\mathrm{A}$ and $\mathrm{B}$ are different toll, mostly show that the four kinds of difference toll $\tau_{A}^{1} \neq \sigma_{A}^{1} \neq \tau_{B}^{1} \neq \sigma_{B}^{1}$. The regional government of toll road makes different toll for local traffic and cross-regional traffic on the basis of the regional economic development. The local government formulates toll policy $\tau_{i}^{1}<\sigma_{i}^{1}$ when the toll goal mainly alleviates congestion.

Because the major direct cause of congestion is an increased transport vehicles of local road, the other is that local region wants to gain additional economic benefits by encouraging the ecdemic economy to promote the local economy on the policy of lower cross-regional vehicles charge while alleviating congestion. The third reason is that it doesn't have a unified pricing method and unified approval agency about toll standard of toll roads in China ${ }^{6}$. In order to obtain the more interests, the adjacent government must correspondingly formulate toll policy which is suitable for the local development. Because road B is downstream of road A, the situation $\tau_{A}^{1}>\tau_{B}^{1}, \sigma_{A}^{1}>\sigma_{B}^{1}$ will appear more according to related theory.

Another expressions are the corresponding same toll pricing standard $\tau_{A}^{1}=\tau_{B}^{1}, \sigma_{A}^{1}=\sigma_{B}^{1}$ and the cross same $\tau_{A}^{1}=\sigma_{B}^{1}, \sigma_{A}^{1}=\tau_{B}^{1}$ of road A and B. Although road A and B belong to two regions, they are the same channel on the ultimate sense. For the situation $\tau_{A}^{1}=\tau_{B}^{1}, \sigma_{A}^{1}=\sigma_{B}^{1}$, both the local and cross-regional transportation are the same; For the situation $\tau_{A}^{1}=\sigma_{B}^{1}, \sigma_{A}^{1}=\tau_{B}^{1}$, the local transport vehicles on the road $A$ is the cross-regional vehicles on the road $B$; So the vehicle of the region $\mathrm{A}$ and $\mathrm{B}$ does not exist any geographic discrimination, toll both the road $\mathrm{A}$ and road $\mathrm{B}$ are the same. But the vehicles outside the region $\mathrm{A}$ and $\mathrm{B}$ are unable to enjoy invisible interests. The situations $\tau_{A}^{1}=\tau_{B}^{1}, \sigma_{A}^{1}=\sigma_{B}^{1}$ and $\tau_{A}^{1}=\sigma_{B}^{1}, \sigma_{A}^{1}=\tau_{B}^{1}$ occurs mostly in the underdeveloped economical regions, these adjacent regions rapid develop economy by collaboration, and provide convenience which foreign resources enter the local by the pricing. Goals of two regions do not obtain the interests each other, but provide convenience for the development each other; it should represent alliance solidarity against the foreign foe. The above are two idealized equilibrium in the game process of $\tau_{A}^{1} \neq \sigma_{A}^{1} \neq \tau_{B}^{1} \neq \sigma_{B}^{1}$ pricing strategy, the two kinds of special pricing strategy can make toll road from the transportation channel and drive local economic take-off.

\subsection{Uniform toll for the road $A$ and $B\left(\theta_{A}^{2}, \theta_{B}^{2}\right)$}

There are two kinds of performances for both uniform toll on the road A and B: the same toll $\theta_{A}^{2}=\theta_{B}^{2}$ and the different $\theta_{A}^{2} \neq \theta_{B}^{2}$. Base on which the government and relevant manager is rational social man, there is no regional discrimination, and uniform toll for the local and cross-regional transportation vehicles when the social development level and civilization degree of the two adjacent regions are high. Sure that A high degree of civilization refers to the consciousness of peoples' equal and the consciousness is not affected by the law, and the high level of social development refers to the regional strategy beyond social purpose, the purpose of toll are beyond the aim of economic development. 
The pricing behaviour of $\theta_{A}^{2}=\theta_{B}^{2}$ would happen that toll solves the problem of congestion, and not a strong economy ${ }^{7}$. It can occur in the following reality: the economic development level of two adjacent regions is similar and civilization degree is higher. They form alliances to gain the regional interests, and implement the same equal charge standard for vehicles in the federal region. For example, several regions in central are likely to go together for the regional benefit when the central region connects to the coastal region. But the charging strategy is a very ideal, and it is few in reality.

The pricing behaviour of $\theta_{A}^{2} \neq \theta_{B}^{2}$ would happen that social development level is higher, but different regions have difference level, different degree in the same category in the other words. Although the social development level of two adjacent regions is higher, Depending on different development conditions lead to the standards' nuances beyond the uniform toll. Before reaching $\theta_{A}^{2}=\theta_{B}^{2}$, it would be happen to war about the price game in order to realize their own benefit.

\subsection{Local transport toll for two roads $\left(\sigma_{A}^{3}, \sigma_{B}^{3}\right)$}

For a single road, only charges the local transport can be said to be a pure excess of local resources, but also a suspect of blindly stimulating the economy. Usually, when a region is relatively well developed, the government will consider a variety of social problems produced by regional economy, such as congestion and environmental issues. On a regional basis, the local vehicle must be the cause of local congestion, and cross-regional vehicles will also result in more air pollution. So, if road pricing is not being used to promote local economic development, and more consideration is given to road congestion, the region will only charge for local transporters. To the two roads linked to each other conducting of fee policy: only local transport vehicles. In fact, the congestion has been transferred, transferred to the road connected, increasing the burden on other roads, so as to relieve congestion in the region's roads. These are the result of a excessive resource. Only charging for the local transport may be a blind stimulating economic activity. In order to bring external resources to region, in consideration of immature situation, it will simply charge different fees for the local and cross-regional transport vehicles. The most direct way is to only charge the local transport vehicles to curb the growth of local transport vehicles. However to the two roads $\sigma_{A}^{3}=\sigma_{B}^{3}$ strategy is a real comparison. When two regions are exposed to different economic pressure, there will be different uniform toll on their different region $\sigma_{A}^{3} \neq \sigma_{B}^{3}$. Similarly, uniform toll in their respective regions on a different situation $\sigma_{A}^{3} \neq \sigma_{B}^{3}$ will appear when two regions of the road is not the same congestion.

\subsection{Cross-regional transport toll for two roads $\left(\tau_{A}^{4}, \tau_{B}^{4}\right)$}

On a toll road in the region, only cross-regional toll appears when there is too much crossregional vehicles. This charging method is based on the reason that the congestion caused by too much road vehicles. Specifically, cross-regional vehicles are relative more than the local transport vehicles, and the former one accounting for in a large proportion in the total traffic volume. In order to get more consumer surplus, it charge tolls targeted on cross-regional vehicles to relieve congestion. Two roads connected to the region only to perform toll for 
cross-regional vehicles in order to avoid excessive use of foreign vehicles lead to road congestion and to develop local strategies. When the two roads are congested because of the extent of cross-regional traffic and too many vehicles to achieve the same degree of congestion, it will work out the same toll rates come. When the two roads are congested because of cross-regional traffic of vehicles, it will not work out the different toll rates $\left(\tau_{A}^{4} \neq \tau_{B}^{4}\right)$.In addition, we only charge for cross-regional vehicles to a certain extent in order to protect local transport companies, to avoid the introduction of external resources and promote the development of local transport. In the long term, only charging for cross-regional vehicles policy is to avoid sustained economic growth and protect local transportation enterprise development. But there are advantages and disadvantages; the bad thing is likely to result in the difficult entry of foreign resources.

\subsection{Local transport toll on a road and cross-regional transport toll on other $\operatorname{road}\left(\sigma_{A}^{3}, \tau_{B}^{4}, \tau_{A}^{4}, \sigma_{B}^{3}\right)$}

Such one road with local transport charges and the other with different policy connected to a cross-regional toll, although it seems that different regions react differently to road congestion. But there is actually a focus of regulation, this situation generally it does not appear only in the case of higher management intervention. About $\left(\sigma_{A}^{3}, \tau_{B}^{4}\right)$, In the region $\mathrm{A}$, due to the implementation of the policy only to the local transport vehicle fee, the vehicle travelling on the road A will be charged. But the road B is a series on the road A, when the local vehicle travelling from road A to road $\mathrm{B}$, the vehicle becomes a cross-regional traffic of vehicles, according to the only way to cross-regional toll from vehicles strategy $\mathrm{B}$, and the car also need to pay tolls. So vehicles belong to region A will be charged twice. Such cases are rarely happened. When regional of road $\mathrm{A}$ is to attract foreign investment or it regards that the causes of congestion is excessive local vehicles, road A will be performed only the local toll policy. When regional economic of road B is very well developed or it considered foreign vehicles would have impact on local transport, the road B will execute only the policy of cross-regional toll. There may be a simple problem of overcrowding that led to the emergence of the pricing strategy. Whatever the reason, when the amount of the difference between the two is exactly the same or close, it will work out strategies $\sigma_{A}^{3}=\tau_{B}^{4}$. If the two are not at the same degree, as a social rational person, it will develop a pricing strategy $\sigma_{A}^{3} \neq \tau_{B}^{4}$. Similarly, it could explain the reason of pricing policy making $\left(\tau_{A}^{4}, \sigma_{B}^{3}\right)$.

Besides the above five kinds of pricing strategy, the following pricing strategy for crossregional toll transport corridor: combination of different toll and uniform toll for the road, combination of different toll and local toll for the road, combination of different toll and Cross-regional toll for the road, combination of uniform toll and local toll for the road, combination of uniform toll and Cross-regional toll for the road. But we can get outcome based on the above analysis for reasons, so there is not much elaboration.

\section{Conclusion}

Cross-regional toll road transport corridors come across different administrative regions on the space, and the construction unit of different regions is not the same, this makes that the government must firstly consider whether to bring the greatest local surplus when price decision of the regional toll road, then consider whether or not the total social surplus would 
be a loss. It makes that the different regions have different charge standard, lastly happen that the same cross-regional transport corridor has different toll standard. This paper divides vehicle into local and cross-regional transportation on the viewpoint of discriminating road users. When connecting toll of two roads, the comprehensive pricing strategy can be divided into 10 groups according to different of local and cross-regional toll standard for each road. Base on analysing the standard of five kinds of special pricing, it is concluded that the different comprehensive standards of cross-regional toll transportation channel is in connection with the economic development, social question, governmental regulation and civilization process.

\section{Acknowledgements}

This research is supported by the Central University Special Foundation in University under Grant No.310823150021、2014G6235034 and 310823151008.

\section{References}

1. URL: http://jtyss.ndrc.gov.cn/zcfg/201207/t20120723_493124.html (23. 7. 2012.).

2. W. Zhang, Transport corridor system analysis, J. Journal of Transportation Systems Engineering and Information Technology. Ei. 1 (2001) 134-139.

3. M. Mao, Y. Pu, Review of transportation corridor study, J. World Sci-tech R\&D. Ei. 28 (2006) 76-81.

4. J. Fan, P. Bai, Road congestion pricing strategy choice on competition state, J. Statistics \& Decision. Cssci.16 (2013) 32-36.

5. G. Dong, D. Zhu, Strategic congested pricing equilibrium on multi-vehicle of competitive logistics corridor, J. Systems Engineering-Theory \& Practice. Ei. 32 (2012) 1213-1221.

6. Y. Liu, Y. Gao, The countermeasures study on perfecting our country's management of the expressway toll collection, J. Price: Theory \& Practice. Cssci. 10 (2010) 19-20.

7. L. Jiang, C. Su, Fenghua WEN, et al, Express way toll policy research based on congestion pricing model, J. Management Review. Ei. 25(2013) 25-36. 